\title{
KAJIAN MORFOSEMANTIS TERHADAP SERAT CENTHINI
}

\author{
Junanah
}

Dosen FIAI Universitas Islam Indonesia Yogyakarta. Email: junanah@yahoo.com

\section{Abstract}

The article explains the deviation of Arabic language absorbed by Serat Centhini from linguistics point of view. Until now, there is an opinion that it has a deviation of the use of Arabic language in Serat Centhini. The study is important to conduct, for linguistically it implicates on the changes of sound, form and meaning of the Arabic absorbent in the Serat Centhini itself.

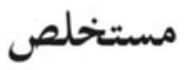

تبحث هذه المقالة عن مدى التغير الطارئ على الكلمات العربية التي استعارها مؤلف كتاب سرات تشنطيني (Serat Centhini) التراثي الإندونيسي، وذلك من وجهة نظر لسانية. ففي أوساط المهتمين بالأعمال الأدبية تشيع وجهة نظر بأن كثيراً من الكلمات العربية المستعارة في الكتاب المذكور قد لحق هـا تغيرات كبيرة تشكل انحرافاً عن اللسان العربي الأصيل، وهو الأمر الذي يستتبع تغيراً في شكل وصوت ومعنى الكلمات التي يتم تحريفها، وهو ما تسعى المقالة الحالية لاستكشافه.

Keywords: Serat Centhini, Kata Serapan, Linguistik, Morfosemantis

\section{A. Pendahuluan}

Serat Centhini adalah karya sastra Jawa yang sarat dengan berbagai ilmu didalamnya, sehingga orang Jawa menyebutnya dengan Ensiklopedi Kebudayaan Jawa, karena isinya sangat sarat dengan berbagai ilmu pengetahuan di antaranya meliputi: sejarah, pendidikan, geografi, arsitektur, pengetahuan alam, falsafah, agama, 
tasawuf, mistik, ramalan, sulapan, ilmu magi (kekebalan, sirep dan ilmu penjahat), perlambang, adat istiadat, tata cara (perkawinan, pindah rumah, berganti nama, menerima tamu dan selamatan dalam daur hidup), etika, pengetahuan sifat manusia (psikologi), ilmu agama Islam (sudah barang tentu kosa kata Arab banyak diserap di dalamnya).

Meskipun demikian, tidak banyak orang yang tertarik untuk mengkajinya, karena karya aslinya sudah sulit untuk ditemukan. Secara historis dijelaskan bahwa ada beberapa jilid dari Serat Centhini ini berada di Belanda, karena Paku Buwana V menghadiahkannya kepada ahli bahasa Jawa dari Belanda. Selain itu, seandainya ada yang mengetahui tentang Serat Centhini ini, biasanya hanya sebagian-sebagian, malah ada yang punya kesan Serat Centhini hanya merupakan karya sastra porno. Penjelasan ini menunjukkan bahwa ada kontroversi dan paradoks dari isi Serat Centhini. ${ }^{1}$

Serat Centhini adalah sebuah karya sastra klasik Jawa berbentuk tembang yang ditulis pada permulaan abad XIX dengan candra sangkal: Paksa Suci Sabda $\mathrm{Ji}=$ tahun Jawa $1742=$ Masehi $1814,{ }^{2}$ merupakan kekayaan alam pulau Jawa. Maksud penulisan Serat Centhini ini tercantum dalam bait permulaan yang disebut manggala. ${ }^{3}$ Istilah sastra Jawa secara praktis diartikan sebagai suatu bentuk aktivitas tulis menulis dari para pujangga Jawa untuk mengungkap nilainilai dan pandangan hidup dalam lingkup budaya Jawa. Kebudayaan ini memiliki elemen-elemen yang bersifat pluralistik (majemuk) yang berakar pada

1 Menurut terjemahan bebas dari Elizabeth D. Inandiak yang membuktikan adanya kekontroversian isi Serat Centhini adalah sebagai berikut: "Ketabuilah dengan baik, Dinda arti salat adalah berbicara dengan zat Allah. Salat adalah memuaskan pikiran pada zat dan bukan lainnya. dan zat adalah welas kasih...' Baca buku saduran Indandiak, Elizabeth D., Empat Puluh Malam dan Satunya Hujan, terj. Lesmana, Laddy, (Yogyakarta: Galang Press, 2004), kemudian bandingkan dengan terjemahan dalam buku sadurannya yang lain, di antara isinya berbunyi: "Cibolang pintar menebak hasrat wanita, ia bisa semaunya memperpendek atau memperpanjang zakarnya sesuai ukuran farji yang tersaji, ia mengenali setiap ceruk dan lekuk daging, sumber kenikmatan....” Baca buku saduran Indandiak, Elizabeth D., Minggatnya Cebolang” terj. Lesmana, Laddy, (Yogyakarta: Galang Press, 2004).

2 Lihat dalam Ceramah Kamajaya, Karkono Pk. "Serat Centhini (Relevansinya Dengan Masa Kini)", Di Balai Pustaka Jakarta pada hari Jumat Pon, 2 September, (Yogyakarta: Yayasan Centhini, 1988) hal. 5-11

mangun reh cariteng dangu, sanggyaning kawruh Jawa, ingimpun tumrap kakawin, mrih tan kemba karya dhanganing wardaya ..... " (..... menggubah cerita lama, (yang memuat) segala-gala kawruh Jawa, dihimpun dalam bentuk tembang, agar menyenangkan hati (pembaca/ pendengarnya) Lihat dalam "Serat Centhini Relevasinya dengan Masa Kini”, 1988, makalah dari Ceramah Kamajaya Pk., H. Karkono, di Balai Pustaka pada hari Jum’at Pon, 2 September 1988, hal. 17. 
etika, agama-agama yang berkembang dalam masyarakat Jawa. Narasi ini memperkuat argumen bahwa manuskrip dan tradisi lisan Nusantara sarat dengan kandungan local wisdom (kearifan lokal). Bentuk teks dalam manuskrip dan teks dalam tradisi lisan ini kemudian berubah dan berkembang sesuai lingkungan geografis zamannya. ${ }^{4}$

Pertemuan etika, agama, terutama Islam dan kearifan lokal masyarakat Jawa di atas menimbulkan suatu sintesa yang harmonis dan kemudian menjadi prototipe dari Islam gaya Jawa yang oleh Geertz disebut sebagai Religion of Java dengan ragamnya yang dapat dibedakan menjadi tiga, yaitu santri, abangan, dan priyayi. Dalam kaitan ini, aspek Islam sangat kental terdapat dalam budaya Jawa, salah satunya terlihat pada aktivitas sastra. Gambaran ini mendeskripsikan mengenai proses Islamisasi budaya Jawa (akulturasi budaya) yang menimbulkan persinggungan dengan budaya lokal dan memunculkan sintesa sebagai Islam Jawa. ${ }^{5}$

Akulturasi budaya yang terjadi di Jawa terekam dan tergambar dengan jelas dalam Serat Centhini. Fenomena ini oleh Dr. Th. Pigeaud ${ }^{6}$ dalam Kamajaya, disebut sebagai Ensiklopedi Kebudayaan Jawa; karena isinya sangat sarat dengan berbagai ilmu pengetahuan diantaranya berisi mengenai agama Islam (sudah barang tentu kosa kata Arab banyak diserap di dalamnya) tentang ilmu, mengenai gending, tentang tari, penilaian baik buruk hari, mengenai tembang (nyanyian), tentang masakan Jawa, lawak, pelacuran dan cerita dari masyarakat lokal. ${ }^{7}$

Terkait dengan kosa kata bahasa Arab yang diserap dalam Serat Centhini ini terdapat suatu pernyataan dan penilaian bahwa telah terjadi penyimpangan bahasa Arab dari aslinya dalam Serat Centhini. Atas penilaian ini, secara akademis membutuhkan kajian lebih mendalam betulkah bahasa Arab dalam Serat Centhini

4 Marsono, Kearifan Lokal dalam Perubahan Lingkungan pada Manuskrip dan Tradisi Lisan, (makalah workshop, di hotel Saphir pada tanggal 22-23 September 2006).

5 Sofwan,Ridin dkk, Islamisasi di Jawa, (Yogyakarta: Pustaka Pelajar, 2000), hal. 161.

6 Seorang sarjana Belanda yang banyak mempelajari dan menulis tentang literatur Jawa, menulis dalam bukunya De Serat Tjebolang en de Serat Tjentini (1933), berpendapat bahwa karena isinya yang penting, pastilah kitab itu berharga sebagai: encyclopedsche beschrijvingen en gewooten (ungkapan ensiklopedik tentang adat-istiadat (Jawa) (lihat dalam "Serat Centhini Relevasinya dengan Masa Kini”, 1988), hal. 5.

7 Kamajaya, Serat Centhini Relevasinya dengan Masa Kini, 1988, hal. 17, dan Poerbatjaraka, Kepustakaan Djawi, Cet. 3, (Djakarta: Djambatan, 1957), hal. 150-151. 
itu sudah mengalami penyimpangan dari aslinya. Hal ini penting dilakukan karena secara linguistik berimplikasi pada adanya perubahan bunyi kata serapan bahasa Arab, perubahan bentuk kata serapan bahasa Arab dan perubahan makna kata serapan bahasa Arab dalam Serat Centhini itu. Oleh sebab itulah peneliti ingin meneliti sejauh mana penyimpangan bahsa Arab yang diserap dalam Serat Centhini dari sudut pandang ilmu bahasa (linguistik)

\section{B. Tinjauan Historis Serat Centini}

Secara historis, Serat Centhini merupakan hasil karya sastra Jawa yang masuk pada genre Jawa Baru yang sudah terpengaruh oleh ajaran Islam. Menurut P.J. Zoetmulder ${ }^{8}$ batas-batas antara kebudayaan barat dan timur sangatlah relatif. Artinya, batas-batas itu tidak dapat digariskan secara tegas dan memisahkan antara keduanya. Oleh karena itu dijelaskan pula tentang keselarasan kebudayaan dan kenyataan adanya perpaduan kebudayaan barat dan timur. Dalam penjelasan ini, Zoetmulder mengatakan bahwa induk kebudayaan-kebudayaan di dunia adalah Timur Tengah, maka baik kebudayaan Barat maupun kebudayaan Timur tidak pernah terisolir dari dunia luar.

8 Beliau adalah orang Belanda yang pada tahun 1939 oleh pemerintah Belanda ditugaskan untuk mengadakan penelitian tentang pendirian sebuah Faculteit der Letteren. (Lihat makalah Darmanto Jatman dalam Seminar Nasional "Meninjau Kembali Kajian Jawa" dalam rangka 100 tahun Prof. Dr. P.J. Zoetmulder, S.J. di Universitas Sanata Darma, 9-10 Februari 2006, yang kemudian beliau secara intensif meneliti dan mengkaji budaya Jawa sampai ke sastra Jawa Kunonya, dan beliau dalam menjalankan misinya melalui Universitas Sanata Darma (USD) sampai beliau meninggal. Selain mengabdi penuh dalam kajian Jawa Kuno, beliau telah mewariskan semua ilmunya dalam bentuk karya tulis baik berupa buku maupun kamus Jawa Kuno, yang semua kekayaan beliau tersebut tersimpan dalam perpustakaan Artati (nama samaran beliau dalam karya tulis) di USD. Di Perpustakaan Artati tersimpan berbagai macam buku yang menggambarkan khazanah Jawa, baik segi budaya, karya sastra, linguistik dan segala sesuatu yang mendukung semua kegiatan beliau, termasuk buku-buku bacaan beliau yang menjadi sumber inspirasi yaitu buku-buku cerita detektif, karena menurut beliau dari cerita detektif tersebut, beliau terinspirasi untuk selalu meneliti. Karena jasa beliau terhadap perkembangan dan pelestarian Budaya Jawa dan sastranya, maka pada 100 tahun usia beliau (berarti beliau lahir tahun 1906) karena Universitas Sanata Darma Yogyakarta (USD), memperingati 100 tahunnya, dengan mengadakan seminar nasional pada tanggal 9-10 Februari 2006. Selain meneliti tentang budaya dan sastra Jawa, Zoetmulder juga menyumbangkan pemikirannya dalam bidang religi maupun filsafatnya. Diantara karya tulis beliau adalah: Cultuur Oost en West (1951), Die Hochreligionen Indonesiens (1964), The Significance of the Study of Culture and relegions for Jawa Historiografi (1965), The Culture Background of Jawan Politics (1967), beberapa artikel yang dimuat dalam Jurnal Studien yaitu R. Artati). Karya-karyanya ini memaparkan permasalahan kebudayaan, religi, dan filsafat Barat dan Timur. 
Sebagai pendukung penyataan ini, Zoetmulder mengungkapkan bahwa dalam kebudayaan Islam ada perpaduan kebudayaan Timur dan Barat. Sementara itu, kebudayaan Roma berkiblat ke Timur. Selanjutnya, dalam mahakaryanya dalam bidang kebudayaan, religi, dan filsafat yaitu Pantheism and Monoism in Javanese Suluk Literatur: Islamic and Indian Mysticism in an Javan Setting (disertasinya tahun 1935) ${ }^{9}$, Zoetmulder menyoroti ajaran sastra suluk sebagai puncak penghayatan mistik yang paling dalam tradisi kejawen dinamakan ngelmu sangkan - paran. Dalam disertasinya ini, Zoetmulder menggunakan Serat Centhini, Serat Wirid, Kitab Bonang, Kitab Tuhfah (juga di dukung beberapa karya sastra lain) sebagai bahan kajiannya. Dengan demikian kajian Zoetmulder tentang suluk dalam sastra jawa berdasarkan ajaran tasawuf dan ajaran filsafat India.

Dari uraian di atas nampak bahwa karya-karya Zoetmulder ternyata banyak memberi sumbangan bagi khazanah sastra Jawa khususnya satra Jawa. Pada awal pergulatannya di Jawa (Jawa) Zoetmulder banyak mempelajari kehidupan spiritual masyarakat Jawa antara lain melalui karya sastra, dalam hal ini sastra Suluk Jawa (sastra Jawa yang mengungkapakan ajaran mistik terutama mistik Islam yang berpadu dengan budaya kejawen). Suluk yang menjadi bahan studinya ini berbentuk tembang macapat. Ketertarikannya dalam bidang sastra suluk Jawa berkembang ke genre sastra yang lain yaitu sastra Jawa Kuna (dan juga sastra Jawa Pertengahan). Disini nampak perjalanan Zoetmulder dalam khazanah sastra Jawa ini jika dialurkan secara lurus memberi gambaran sejarah sastra Jawa. Dalam hal ini SC merupakan salah satu kajian beliau, tetapi beliau memfokuskan pada filsafat dan mistiknya, sementara peneliti memfokuskan pada kata serapan bahasa Arabnya.

Hingga saat ini, pengembangan sastra Jawa dapat dikatakan masih belum jelas. Oleh karena itu, dari hasil mencermati karya-karya Zoetmulder, dalam tulisan ini disampaikan pemikiran tentang "perjalanan" sastra Jawa. Dalam Kalang Wan, Zoetmulder mengungkapkan bahwa prasasti Sukabumi yang bertanggal 25 Maret 804 M (abad 9) merupakan karya berbahasa Jawa Kuna yang bertanggal paling tua (sejauh belum ditemukan prasasti atau karya sasrta lain). Ini berarti perjalanan

9 Adji, Fransisca Tjandrasih, "Karya-karya Zoetmulder dan Sejarah Sastra Jawa", makalah Seminar Nasional "Meninjau Kembali Kajian Jawa" dalam rangka memperingati 100 tahun Prof. Dr. Zoetmulder, S.J. USD, 9-10 Februari 2006. 
sastra Jawa kuna dapat dikatakan barawal dari bawah Jawa Tengah pada abad 9 . Untuk lebih jelasnya, perjalanan sastra Jawa akan diuraikan dalam bentuk bagan sebagai berikut. ${ }^{10}$

\section{Bagan 1}

\begin{tabular}{|c|c|c|c|}
\hline $\begin{array}{l}\text { ABAD/ } \\
\text { TAHUN }\end{array}$ & KERJAAN/RAJA & $\begin{array}{l}\text { GENRE } \\
\text { SASTRA }\end{array}$ & KETERANGAN \\
\hline 9 & Jawa Tengah & Jawa Kuna & $\begin{array}{l}\text { Prasasti bertanggal paling tua yang } \\
\text { menggunakan bahasa Jawa Kuna }\end{array}$ \\
\hline $10 / 930$ & $\begin{array}{l}\text { Jawa Timur. Wangsa } \\
\text { Sindok, Dharmawangsa } \\
\text { Teguh }\end{array}$ & Jawa Kuna & \\
\hline $11-12 / 1016$ & $\begin{array}{l}\text { Jawa Timur / Erlangga } \\
\text { Bali/anak bungsu } \\
\text { Kediri }\end{array}$ & $\begin{array}{l}\text { Jawa Kuna } \\
\text { Bali Kuna/ } \\
\text { Jawa Kuna }\end{array}$ & $\begin{array}{l}\text { Sastra Jawa Kuna dan sastra Bali kuna } \\
\text { berdampingan namun akhirnya di } \\
\text { Bali sastra Jawa kuna lebih } \\
\text { berkembang banyak karya sastra yang } \\
\text { menyebutkan raja Kediri sebagai } \\
\text { dewa Raja }\end{array}$ \\
\hline 13 & Singasari & Jawa Kuna & \\
\hline \multirow[t]{4}{*}{$14-15$} & $\begin{array}{l}\text { Majapahit } \\
\text { Bali }\end{array}$ & Jawa Kuna & $\begin{array}{l}\text { Ada karya sastra Jawa Kuna yang } \\
\text { tidak begitu jelas ditulis di Jawa dan } \\
\text { di Bali }\end{array}$ \\
\hline & & \begin{tabular}{|l|} 
Jawa \\
Pertengahan
\end{tabular} & $\begin{array}{l}\text { Dijumpai karya sastra denga bahasa } \\
\text { yang berbeda }\end{array}$ \\
\hline & & $\begin{array}{l}\text { Jawa } \\
\text { Pertengahan }\end{array}$ & $\begin{array}{l}\text { Dijumpai karya sastra dengan bahasa } \\
\text { yang berbeda. }\end{array}$ \\
\hline & Jawa & Jawa Pasisir & $\begin{array}{l}\text { Peralihan ideologi hindu ke Ideologi } \\
\text { Islam : pertengahan }\end{array}$ \\
\hline \multirow[t]{4}{*}{$16-17$} & Daha & Jawa Kuna & Mengalami kemunduran \\
\hline & & $\begin{array}{l}\text { Jawa } \\
\text { Pertengahan }\end{array}$ & \\
\hline & Jawa Tengah & Jawa Pesisir & \\
\hline & Jawa Tengah & Jawa Baru & Pengaruh Islam \\
\hline 18-19 & Surakarta & Jawa Baru & \\
\hline $20-?$ & & Jawa Modern & $\begin{array}{l}\text { Tidak lagi mempertimbang-kan } \\
\text { konvensi sastra Jawa secara ketat }\end{array}$ \\
\hline
\end{tabular}

10 Fransisca Tjandrasih Adji, "Karya-karya Zoetmulder dan Sejarah Sastra Jawa”, makalah Seminar Nasional "Meninjau Kembali Kajian Jawa" dalam rangka memperingati 100 tahun Prof. Dr. Zoetmulder, S.J. USD, 9-10 Februari 2006. Kalau melihat bagan diatas, maka SC termasuk pada masa abad 18-19, berada pada kawasan kerajaan Surakarta, termasuk genre Jawa Baru, dan ditulis dengan aksara Jawa Gagrak Anyar, yang menyerap berbagai macam bahasa termasuk bahasa Arab. Untuk dapat membaca dan mengambil data dari SC yang betuliskan aksara Jawa, peneliti harus memadankan antar SC latin yang sudah dicetak, dengan SC Latin yang masih ketikan manual, kemudian dipadankan dengan SC yang bertuliskan aksara Jawa. Pada awalnya, peneliti hanya mengambil data dari SC Lating yang sudah dicetak, tapi kemudian peneliti dapat membaca langsung SC Latin yang masih ketikan manual dan SC aksara Jawa, meskipun hanya sebatas SC jilid IV. V, dan jilid VI. Dari ketiga jilid tersebut, menunjukkan bahwa SC merupakan karya sastra Jawa yang telah dipengaruhi oleh Islam. 
Bagan di atas tidak dimaksudkan untuk menunjukkan batas tegas perlalihan genre sastra yang satu ke genre yang lain. Bagan itu dimaksudkan untuk memudahkan melihat kerangka sejarah sastra Jawa berdasarkan pemikiran Zoetmulder dalam karya-karyanya. SC merupakan salah satu karya sastra yang tak lepas dari penelitiannya.

Dalam ketiga jilid SC, baik IV, V, maupun VI ${ }^{11}$ terdapat bukti bahwa pengaruh Islam sangat kuat, sehingga kata serapan bahasa Arab terutama yang berkaitan dengan ajaran Islam. Meskipun demikian, SC tidak sepenuhnya berisi tentang tuntunan ajaran Islam, karena pada masa itu sudah didahului oleh pengaruh ajaran agama sebelumnya. Hal inilah yang menyebabkan Rasyidi menyimpulkan dalam disertasinya, bahwa bahasa Arab yang ada dalam SC sudah tidak menggambarkan ajaran Islam murni. Dalam jilid IV, terdapat Asma' al-husna semuanya. Meskipun demikian ada juga terselip asma yang bukan termasuk asma' al-husha, yaitu Almuti.

Selain itu, isi SC diawali dengan pergulatan politik antara Sunan Giri (Jawa Timur) dan Sultan Agung (Raja Mataram Islam). Sunan Giri termasuk salah satu wali sanga, sementara Sultan Agung merupakan raja Mataram Islam. Hal ini menunjukkan bahwa Islam sangat mempengaruhi dalam karya tulis SC yang adiluhung.

\section{Kontak antara Bahasa Jawa dengan Bahasa Arab}

Kontak antara bahasa Jawa dengan bahasa Arab diyakini telah berlangsung sejak penyebaran Islam di Nusantara. Pada masa itu bahasa Jawa masih merupakan bahasa Melayu sedangkan bahasa Jawa merupakan bahasa daerah orang Jawa khususnya Jawa tengah. Menurut Al-Attas nama kepulauan Nusantara disebutnya sebagai kepulauan Melayu-Jawa. Orang-orang Arab yang mula-mula datang menyebarkan Islam di kawasan tersebut sengaja memilih bahasa Melayu sebagai bahasa pengantarnya ${ }^{12}$. Islam kemudian mengalami perkembangan pada masa kejayaan kerajaan Malaka (abad xiv-xvi). Pada masa inilah bahasa Melayu diperkaya oleh bahasa Arab bersamaan dengan perkembangan Islam ${ }^{13}$. Pengaruh bahasa Arab

11 Kamajaya, Serat Centhini (Suluk Tambangraras), (Yogyakarta: Yayasan Centhini), 1988 jilid 4, dan bandingkan dengan sadurannya Ngabei Ranggasutrasna, dkk., Centhini TambangrarasAmongraga, (Jakarta: Balai Pustaka, 1999), jilid 4.

12 Syed Naguib Al-Attas, Preliminary Statement on A General Theory of The Islamisation of The Malay-Indonesion Archipelago, (Kuala Lumpur: Dewan Bahasa dan Pustaka, 1969), hal. 56.

13 Hamidy, Metode Penelitian Kualitatif (Malang: Universitas Muhammadiyah Malang, 1995), hal. 6, dan bandingkan dengan pendapat Abdul Chaer dan Leonie Agustina, SosiolinguistikPerkenalan Awal (Bandung: Angkasa, 2004), Cet. II, hal. 84-92. 
terhadap bahasa Melayu semakin intensif dengan dipakainya tulisan Arab untuk menuliskan bahasa Melayu. Selanjutnya, karya-karya sastra ditulis dengan tulisan Jawi (Arab Melayu). Naskah-naskah kesusastraan Melayu tertua yang ditulis dengan huruf Jawi diperkirakan berasal dari abad ke 16. Pada abad ke 17 bahasa Arab dipakai untuk menuliskan buku-buku keagamaan di kepulauan Nusantara ${ }^{14}$

Pengaruh bahasa Arab terhadap bahasa Melayu tentu saja sejalan dengan perkembangan pengaruh Islam terhadap kepulauan Melayu-Jawa yang berlangsung sampai sekarang. Pemakaian tulisan Jawi dimulai kira-kira abad ke 13 sampai abad ke 20. Prasasti tertua bertulisan Jawi ditemukan di Kuala Berang Trengganu, bertahun 1303. Sekarang tulisan Jawi masih dipakai di Malaysia (dipakai pada surat kabar Utusan Melayu, sehingga Utusan Melayu mempunyai dua versi, yaitu yang bertuliskan Latin dan bertuliskan Jawi) dan Brunei Darussalam.

\section{Bilingualisme Jawa-Arab}

Adanya kontak bahasa Arab dan Jawa yang disebabkan oleh kontak budaya antara Islam dan Jawa setelah agama Islam masuk ke wilayah Jawa, maka menyebabkan orang Jawa menjadi dwibahasawan. Orang Jawa yang telah menganut agama Islam, maka mereka secara sukarela menjadi dwibahasawan baik aktif maupun pasif. Secara aktif, orang Jawa dalam sholatnya menggunakan bahasa arab, yang diikuti dengan dzikir sehabis sholat. Secara pasif, dalam lembaga pendidikan di pesantren salaf, mereka dalam menerjemahkan kitab kuning yang mereka baca

14 Nabilah Lubis, Suntingan Naskab Zubdaz al-Asrar fi Tahqiq Ba'd Masyarib al-Akbyar Karya Syeh Yusuf A-Taj,1991, (disertasi, IAIN Syarif Hidayatullah, Jakarta), hal. 7. Pada kenyataannya faktor kebahasaan menunjukkan bahwa betapa efektifnya kontak intelektualkeagamaan itu sangat berpengaruh kepada pembentukan budaya Melayu-Jawa. Bahasa Melayu yang sebelumnya merupakan bahasa pasaran, mengalami perubahan besar bagaikan suatu revolusi. Selain diperkaya perbendaharaan kata-katanya dengan istilah-istilah dan perkataan-perkataan Arab dan Persi, bahasa Melayu-Jawa sampai pada abad ke enam belas telah menjadi bahasa sastra dan agama (Al-Attas, Preliminary Statement on A General Theory of The Islamisation of The Malay- Indonesion Archipelago, 1990, hal. 62). Dan bandingkan dengan Baroroh-Baried Babasa Arab dan Perkembangan Bahasa Indonesia (Yogyakarta: UGM,1970), hal. 5 menyatakan bahwa bahasa Melayu menjadi lingua franca di wilayah tersebut. Dan bandingkan dengan bukunya Collins, James T, Malay, World Language: a short history, (Malaysia: Dewan Bahasa dan Pustaka, 1996), yang sudah diterjemahkan oleh Almanar, Elma Evita, Bahasa Melayu Bahasa Dunia Sejarah Singkat, (Jakarta: Yayasan Obor, 2005), hal. 8-71. 
menggunakan Arab pegon atau Jawi (Melayu), atau secara formal biasanya disebut Arab Melayu. ${ }^{15}$

Orang Jawa sudah mempunyai bentuk penulisan aksara, yang dianggap adilubung leluhur bangsa Jawa sehingga kini ${ }^{16}$. Ia berubah mengikuti urutan waktu dan suasana, dengan jati diri keilmuannya sudah tercatat sejak abad ke $8 \mathrm{M}^{17}$ Seperti bahasa lain, bahasa Jawa yang dituturkan itu amat terikat dengan waktu dan tempat. ${ }^{18}$ Oleh sebab itu, perkembangan aksara Jawa juga ada kaitan dengan perkembangan bahasa Jawa yang lahir sebagai alat komunikasi masyarakat.

Aksara Jawa muncul setelah adanya kontak budaya antara Jawa dengan India. Sebelumnya belum ada bukti yang menunjukkan bangsa Jawa mempunyai aksaranya sendiri. ${ }^{19}$ Aksara Jawa yang ada sekarang adalah hasil dari rekonstruksi aksara Jawa Kuna (kuno). ${ }^{20}$

Sebelum membicarakan aksara Jawi secara terperinci, perlu ditunjukkan warisan aksara Jawa (ancrk) sebelum kedatangan Islam. Aksara Jawi yang menggunakan huruf Arab, yang lebih dikenal sebagai tulisan Pegon atau Arab Gundul hanya ada setelah kedatangan Islam.

\section{a. Huruf Jawi menurut lafadz Arab adalah:}

15 Menurut Shofwani, M.Irfan, dalam bukunya yang berjudul, Mengenal Tulisan Arab Melayu, (Yogyakarta: Adicita, 2005), hal. 9-13, bahwa Arab Melayu masuk ke Indonesia bersamaan masuknya Islam ke wilayah Nusantara, antara abad 12 M/13M. Meskipun demikian, banyak bukti sejarah menunjukkan bahwa masuknya Islam ke Nusantara sudah jauh sebelum abad ke $12 \mathrm{M}$, dengan ditemukannya batu-batu bersurat a.l; di Terengganu (Malaysia), Aceh, Riau, dan daerah-daerah lain (Shafwani, hal. 9), dan masih banyak lagi bukti yang menunjukkan penggunaan Arab Melayu oleh raja-raja Melayu dalam hubungannya dengan negara luar (Shafwani, hal. 10).

16 Riyadi,Slamet, $\mathrm{Ha}-\mathrm{Na}-\mathrm{Ca}-\mathrm{R} a-\mathrm{Ka}$ (Kelabiran, penyusunan, fungsi dan makna) (Surabaya: Yayasan Pustaka Nusantara 1966), hal.1, dan baca Alma Evita Almanar, Babasa melayu Bahasa Dunia(penerjemah) dari Malay World Language: a short history (James T. Collins), (Jakarta: Yayasan Obor Indonesia, 2005), hal. 8-27.

17 Zoetmulder, Kalangwan: Sastra Jawa Selayang Pandang, ,(Jakarta: Djambatan, 1994), hal. 3.

${ }^{18}$ Van der, Molen W.' Sejarah dan Perkembangan Aksara Jawa", dalam Soedarsono dkk. (penyunting), Aksara dan Ramalan Nasib dalam Budaya Jawa, (Yogyakarta: Proyek Javanologi, 1985), hal. 3.

${ }^{19}$ Poerbatjaraka, R.M. Ng \& Tarjan Hadidjaya, Kepustakaan Jawa, (Jakarta: Djambatan,1952), hal. vii.

20 Raffles, Thomas Stamford, The History of Java, Jilid II, (Kuala Lumpur: Oxford University Press, 1982), hal. 370. 
Alif, Ba, Ta, Sa, Jim, Ha, Kho, Dal, Dzal, Ro, Zai, Sin, Syin, Shot, Dlot, Tho, Zho, 'Ain, Ghain, Fa, Qof, Kaf, Lam, Min, Nun, Wau, Ha, Lam Alif, Hamzah, Ya.

b. Bacaan menurut bahasa Jawa adalah sebagai berikut:

Alip, Ba, Ta, Sa, Jim, Ka, Ko, Dal, Dal, Ro, Jai, Sin Sim, Sot, Dot, To,Do, Ngain, Gain, Pa, Kap, Kop, Lam, Mim, Nun, Wawu, Ha, Lam Alip, Amzah, Ya. Pemaparan di atas memperlihatkan sebutan Jawa amat ketara dalam bunyi p, b, ng, dan r. Misalnya, sebutan Zhuhur bertukar menjadi Lohor ${ }^{21}$

\section{c. Pemakaian Huruf Arab Melayu (Jawi) menurut Orang Islam}

Setelah agama Islam masuk Indonesia, mayoritas masyarakat Jawa adalah penganut Islam, akan tetapi adat istiadat yang sudah berlaku, masih banyak dilaksanakan, karena para wali didalam menyiarkan agama Islam menggunakan pendekatan kultural. Hal inilah yang menjadikan sebab masih berlangsungnya faham animisme dan dinamisme, yang berupa takhayul, khurufat dan sejenisnya ${ }^{22}$, yang kalau dinalar sesungguhnya susah untuk diterima. Dalam hal ini Geertz ${ }^{23}$ menyebutkan bahwa nama-nama lain dari syetan, ada bermacam-macam, yang semuanya biasanya berwajah buruk, dan dengan nama yang menyeramkan. Sementara Koentjoroningrat ${ }^{24}$ telah mengumpulkan 87 istilah untuk roh, dan 17 istilak untuk setan.

Pemahaman masyarakat Jawa yang masih heterogen tentang ajaran Islam, maka tidak jarang terlihat adanya fenomerna seperti tersebut diatas. Meskipun pada perkembangan Islam selanjutnya sudah banyak masyarakat Jawa yang mulai sadar akan ketidak benaran adat yang masih banyak dianut oleh sebagian masyarakat Jawa, terutama yang tinggal di pedesaan. Huruf Jawi (Arab Melayu) semakin terbatas pemakaiannya meskipun sudah menjadi tradisi pemakaian huruf itu berlangsung dari era penggunaan $\mathrm{Ha} \mathrm{Na} \mathrm{Ca} \mathrm{Ra}$ Ka hingga kepada penggunaan Alif $\mathrm{Ba}$ Ta dalam bentuk yang telah disesuaikan. Pemakaian huruf Jawi, terutama huruf Alif dalam berbagai kegiatan sudah tampak karena orang Jawa tertarik dengan huruf yang mereka pakai.

Sebagai contoh pada lafadz 'Laqad kuntu' ${ }^{25}$ digunakan untuk mengobati orang sakit gigi. Dalam bahasa Jawa 'untu' adalah gigi. Hal-hal seperti ini tidak jarang

21 Emha Ainun Najib, Slilit Sang Kiai, (Jakarta: Pustaka Utama Grafiti, 1992), hal. 101.

22 Sofwan,Ridin dkk, Islamisasi di Jawa, (Yogyakarta: Pustaka Pelajar, 2000), hal. 119-137.

23 Geertz, Clifford, Abangan, Santri, Priyayi dalam Masyarakat Jawa, terjemahan; Aswab Mahasin (Jakarta: Penerbit Pustaka Jaya, 1981) hal. 19-32.

24 Koentjoroningrat, Kebudayaan Jawa, (Jakarta: PN Balai Pustaka, 1984), hal. 339.

25 Mohamed, Noriah, Aksara Jawi: Makna Fungsi, (Bangi: Pejabat Penerbit University Kebangsaan Malaysia, 1992), hal. 130. 
terjadi dan digunakan dalam pengobatan tradisional. Pada awalnya secara kebetulan orang yang diobati sembuh, maka akhirnya diyakini, dan menjadi sarana pengobatan. Padahal kalau dilihat dari maknanya, hal tersebut tidak ada kaitannya, tetapi karena bunyinya menyerupai, maka mereka pakai. Tradisi pengobatan melalui lafadz Arab, yang diambil dari bunyinya, atau kadangkala hanya berupa beberapa huruf Hijaiyah, yang dimasukkan kedalam air, dan air tersebut dibacakan do'a, mereka meyakini bisa dijadikan obat.

Akhir-akhir ini Bahasa Jawa sering menjadi bahan diskusi dan pembahasan di forum akademisi, sebagai wujud kepedulian terhadap budaya Jawa. Oleh karena kedudukan bahasa Jawa dalam dunia internasional pada dasarnya sama dengan bahasa Arab yang merupakan salah satu dari bahasa internasional dunia, disebabkan kedua bahasa tersebut merupakan bahasa yang memiliki sistem lambang. Hubungan antara Bahasa dan kebudayaan merupakan hubungan yang sub-ordinat, di mana bahasa berada di bawah lingkup kebudayaan ${ }^{26}$. Bahasa merupakan alat komunikasi yang digunakan oleh manusia untuk berinteraksi dalam suatu komunitas. Dengan sebab itulah keberadaan bahasa dalam masyarakat memiliki peranan yang cukup signifikan.

Masyarakat pada umumnya, memerlukan alat komunikasi untuk berinteraksi dengan anggotanya, dan alat komunikasi yang paling efektif adalah bahasa, karena bahasa memiliki beberapa kelebihan jika dibandingkan dengan alat komunikasi yang lain, antara lain:bahasa bersifat produktif, dinamis dan yang paling penting adalah bahasa bersifat manusiawi. Oleh sebab itu, sangatlah wajar ketika pada kondisi di atas, bahasa merupakan kebutuhan mutlak manusia, sehingga terlahirlah bahasa dalam suatu komunitas masyarakat. Bahasa merupakan sistem lambang, berupa bunyi yang bersifat arbitrer, produktif, beragam, dan manusiawi. ${ }^{27}$

Berdasarkan pengertian di atas, maka bahasa merupakan satu kesatuan sistem yang tidak dapat dipisah-pisahkan, antara lambang dan bunyi, bahasa tulis dan bahasa lisan. Oleh karena itu, eksistensi suatu bahasa terletak pada eksistensi lambang dan bunyi. Hal ini diperkuat oleh pendapatnya Ronald Wardhough, ${ }^{28}$ bahwa

26 Chaer, Abdul Linguistik Umum, (Jakarta: PT. Rineka Cipta, 1995), hal. 217.

27 Chaer, Abdul Linguistik Umum... hal. 14.

28 Wardhough, dia menulis dalam bukunya yang berjudul An Introduction to Sociolinguistics sebagai berikut "What is particularly important in both of these attempts at a definition is that 'variety' is defined in term of specific set of 'linguistics item' or 'buman speech patterns' (presumably, sounds, words, grammatical features) which we can uniquely associate with some external factor (presumably, ageographical area or asocial group” (New York: Basil Blackwell Inc,1987), hal. 22. 
keberadaan bunyi juga dipertimbangkan dalam bahasa. Oleh karena itu, ketika salah satu, bahasa lisan dan bahasa tulis, atau bahkan kedua-duanya tidak ada dalam suatu bahasa, maka bisa dikatakan bahwa bahasa itu telah atau akan menuju kepunahan. Bahasa yang memiliki sistem lambang yang ada di dunia ini hanya berjumlah 21 bahasa.

Bahasa Jawa merupakan salah satu bahasa yang masuk dalam kategori bahasa yang memiliki sistem lambang. Oleh yang demikian itu, pada dasarnya keberadaan bahasa Jawa bisa disejajarkan dengan bahasa Arab yang merupakan bagian dari bahasa Internasional. ${ }^{29}$ Namun kebanggaan itu seakan tak bernilai, jika kita sebagai penutur asli bahasa Jawa sudah mulai melupakan dan meninggalkannya, terutama para generasi muda.

Pembahasan diatas menunjukkan bahwa bahasa terlahir dari budaya dan bahasa merupakan bagian dari budaya. ${ }^{30}$ Bahasa dan budaya disini memiliki peranan yang berbeda. Bahasa sebagai alat untuk berinteraksi antar anggota masyarakat dan budaya sebagai alat untuk menunjukkan eksistensi diri (dalam konteks budaya), karena setiap masyarakat memiliki budaya yang berbeda dengan masyarakat yang lain. Maka dari itu, ketika bahasa Jawa sudah mulai dilupakan, maka tidak menutup kemungkinan lambat laun bahasa Jawa akan kehilangan salah satu asset budaya terbesarnya, dalam hal ini adalah bahasa Jawa. Dengan kata lain, melupakan bahasa Jawa berarti akan berdampak pada budaya yang ada. Bahasa dan Masyarakat, menurut pandangan sosiolinguistik, bahasa itu juga mempunyai ciri sebagai alat interaksi sosial dan sebagai alat mengidentifikasi diri. ${ }^{31}$

${ }^{29}$ Lihat Koentjoroningrat, Javanese Culture, (Singapore : Oxford University Press Oxford New York, 1985), hal. 15.

30 Hal ini, semakin diperkuat oleh pendapat dari Koentjaraningrat (1992), menurutnya, isi dari budaya ada 7 macam, yaitu, bahasa, sistem teknologi, sistem mata pencaharian hidup, organisasi sosial, sistem pengetahuan, sistem religi dan kesenian. Pendapat ini semakin memperteguh pendapat tentang kedudukan bahasa terhadap budaya yang bersifat subordinatif. Hubungan bahasa dengan budaya yang kedua adalah bersifat koordinatif. Maksudnya adalah antara bahasa dan budaya memiliki hubungan yang sama, namun memiliki perbedaan peran. Hubungan ini bisa dianalogikan dengan hubungan antara dua sisi keping uang logam yang tidak dapat dipisahkan, namun memiliki peranan atau fungsi yang berbeda pada tiap sisinya.

31 Chaer, Abdul, Linguistik umum , 1995, hal. 19, Berdasarkan uraian di atas, maka fungsi bahasa ada dua, yaitu:1. Sebagai alat interaksi sosial, dan 2. Sebagai alat untuk mengidentifikasi diri. Bahasa sebagai alat interaksi sosial berarti bahasa digunakan sebagai alat komunikasi antara anggota masyarakat dalam lingkungan sosial. 
Setiap anggota masyarakat, memiliki karakteristik masing-masing dalam berbahasa. Dalam suatu kelompok tertentu, kita mengenal adanya istilah dialek, yaitu variasi bahasa dari sekelompok penutur yang jumlahnya relatif dan berada pada satu tempat atau wilayah tertentu. ${ }^{32}$ Karena kondisi geografis dan lingkungan menentukan perbedaan penggunaan bahasa oleh penuturnya. Dalam lingkup individu, kita mengenal istilah idiolek. ${ }^{33}$

Dwibahasawan Jawa sering terkendala oleh dialek dan lidah Jawa yang biasanya berdasarkan aksara Jawa (ancrk), dimana apabila dipadankan antara huruf hijaiyah dengan aksara Jawa, maka ada beberapa yang tidak ada padanannya. Untuk mengatasi hal ini, maka para pakar Jawa memberikan solusi dengan memberikan aksara rekan $^{34}$, yaitu

$k+=k h a(), f+=d z a(\quad), p+=f a(\quad), j+=q a(\quad), g+=$ gha $(\quad)$

Adapun contoh dalam kalimat adalah:
a. Khabar $=k+b /$
b. Faham $=\quad=p+a m \backslash$
c. Dzikir $=\quad=f+i k i l$
d. Zakat $=\grave{O}=j+k A$
e. Ghaib = $=g+I b \backslash$

Penggunaan bahasa yang bergantian karena adanya kontak budaya dan kontak bahasa, maka menyebabkan terjadinya penggunaan bahasa kedua (kata serapan) oleh Dwibahasawan tersebut. Orang Jawa yang telah memeluk agama Islam, mau tidak mau akhirnya menggunakan kata serapan dari bahasa Arab, disebabkan bahasa Arab merupakan bahasa Al-Qur'an (kitabnya orang Islam), dan dalam sholat (ibadah mahdlohnya orang Islam), dimana orang Islam akan menggunakan bahasa Arab setiap hari, minimal dalam sholat dan membaca kitab sucinya.

\section{Penggunaan Istilah Serapan}

Akibat dari kontak bahasa yang menyebabkan terjadinya dwibahasawan, maka berdampak pada penggunaan kata serapan dari bahasa kedua (B2), secara terus menerus, sehingga kata serapan tersebut akhirnya menjadi B1 bagi dwi bahasawan

32 Chaer, Abdul Linguistik Umum ..., hal. 83, dan bandingkan dengan pendapat Partana Paina (penerjemah), Semantik, dari Semantics (Leech, Geofferey), (Yogyakarta: Pustaka Pelajar, 2003), hal. 25- 29.

33 Chaer, Abdul, Linguistik umum (Jakarta: PT. Rineka Cipta, 1995), hal. 82.

34 Sudaryanto (Penyunting), Tata Bhasa Baku Bahasa Jawa, (Yogyakarta: Duta Wacana University Press, 1991), hal. 243. 
tersebut. Kata serapan ini seharusnya sesuai dengan aslinya baik bentuk, bunyi maupun maknanya. ${ }^{35}$ Adapun secara kronologis, perlu adanya pembahasan tentang istilah kata serapan.

Istilah kata serapan diambil dari beberapa istilah asing antara lain:

a. Loan word; kata serapan diambil secara bentuknya (morfem), tanpa penggantian baik sama sekali, sebagian atau secara keseluruhan, misal: kata muslim / musLim ${ }^{36}$ ( / muslim)

b. Loan blends; kata serapan disini sudah terjadi penggantian bentuk (morfem), sehingga yang terjadi adalah terbentuknya kata yang sudah termodifikasi atau sudah bercampur dengan kata asing (bahasa lain), misal kata nraka jahanam / $n]] k$ janm ${ }^{37}$ ( / nâr jahannam)

c. Loan shifts; kata serapan yang secara bentuk dan maknanya sama, akan tetapi secara bunyi (fonem)nya sudah disesuaikan dengan lisan nativenya, yang termasuk dalam jenis ini adalah loan translation; dalam pungutan terjemahan ini sebuah konsep dalam bahasa Arab diterjemahkan ke dalam bahasa Jawa. Jadi yang diserap adalah makna dari konsep tersebut. Kata-kata terjemahannya semuanya adalah kata-kata bahasa Jawa, misal kata maha mulya / mamulY ${ }^{38}$ ( / / al-'azîz)

Dari uraian diatas, kata serapan yang dimaksud dalam SC adalah semua istilah tersebut, karena yang terjadi dalam SC, kadang-kadang kata serapan ada yang masih asli secara bunyi dan maknanya, akan tetapi ada yang bunyinya lain, tapi maknanya masih sama, dan ada yang baik bunyi dan maknanya sudah berubah.

\section{Motif Penggunaan Kata Serapan}

\section{a. Kehematan, Kemudahan, dan Kesingkatan (Kebutuhan)}

Penyerapan kata asing sangat diperlukan, karena ada beberapa kata Jawa yang terlalu panjang, tetapi dengan kata serapan dapat menghemat. ${ }^{39}$ Oleh karena itu, kehematan dan kesingkatan merupakan salah satu faktor penyerapan dalam suatu bahasa.

35 Haugen, Einar, The Ecologi of Language,( Stanford: Stanford University Press, 1972), hal. 83-84 dan bandingkan dengan Poedjosoedarmo, Indonesian Influence on Javanese, (A Thesis, Cornell University, 1967), hal. 49-55.

36 Kamajaya, SC VI, 1988, hal. 104 dan lihat SC VI, hal. 105.

37 Kamajaya, SC IV, 1988, hal. 200 dan lihat SC IV, hal. 144

38 Lihat SC IV, hal. 57, dan Kamajaya, SC IV, 1988, hal. 77

39 Poedjosoedarmo, Soepomo, Indonesian Influence on Javanese, 1967, hal. 55-60, dan bandingkan dengan Moeliono, Masalab Asli dan Asing dalam Bahasa Indonesia, (Jakarta: Gramedia, 1986), hal. 33;Gonda,1991, hal. 30; Halim, 1997, hal. 13. 


\section{b. Kejarangan Bentuk (Efesiensi)}

Kata serapan bahasa lain lebih mudah digunakan karena kadang istilah Jawa lebih sulit untuk difahami, sehingga hal inilah yang mendorng orang Jawa lebih memilih kata serapan. ${ }^{40}$ Menurut Weinreich, ${ }^{41}$ kata yang jarang digunakan, maka akan berakibat kurang stabil menjadi perbendaharaan. Oleh karena itu, maka kata tersebut akan dilupakan dan digantikan dengan kata serapan

\section{c. Keperluan akan Kata Searti (Status) ${ }^{42}$}

Pemakaian kata serapan yang searti dianggap lebih enak didengar daripada dengan kata asli Jawa yang kadang terasa kurang resmi apabila digunakan. Sebab inilah yang mendorong orang Jawa lebih senang menggunakan istilah bahasa lain yang searti daripada bahasa Jawa sendiri

\section{d. Dorongan Gengsi (Prestise)}

Pemakaian kata serapan dari bahasa lain merasa terangkat gengsinya, agar dimasukkan kedalam kelompok orang yang berpendidikan itu bertolak di bahasa yang berstatus tinggi ke arah bahasa yang berstatus rendah ${ }^{43}$. Weinreich ${ }^{44}$ menyebutnya dari bahasa yang dominan ke bahasa yang berubah status lebih tinggi. Gengsi bahasa yang dominan inilah yang menjadi faktor yang mendorong pemungutan. Akibatnya, dirasakan bahwa pungutan lebih bergengsi jika dibandingkan dengan kata asli45.

\section{e. Kekurangan Kemampuan terhadap Bahasa Sendiri (Status Motive)}

Poedjosoedarmo mengatakan ${ }^{46}$, bahwa orang Jawa ada yang merasa kata asing yang biasa mereka gunakan tidak semudah itu digantikan dengan bahasa Jawa itu sendiri. Oleh karena itulah orang Jawa tersebut akan lebih nyaman menggunakan kata asing yang sudah terserap kedalam bahasa Jawa.

40 Poedjosoedarmo, Soepomo, 1967, hal. 57 dan bandingkan dengan Moeliono, Masalah Asli dan Asing dalam Bahasa Indonesia , 1986, hal. 33

41 Weinreich, Language in Contact and Problems, 1953, hal. 91

42 Poedjosoedarmo, Soepomo, 1967, hal. 58.

43 Poedjosoedarmo, Soepomo, 1967, hal. 56, dan bandingkan denganHeah Lee Hsia, The Influence of English on the Lexical Expansion of Bahasa Malaysia, (Kuala Lumpur: Dewan Bahasa dan Pustaka,1989), hal. 17, Gonda, 1991, hal. 51.

44 Weinreich, Language in Contact and Problems, 1953, hal. 92.

45 Haugen, The Ecologi of Language, (California: Stanford University Press: 1972), hal. 199.

46 Poedjosoedarmo, Soepomo, 1967, hal. 56, dan bandingkan dengan Moeliono, Masalab Asli dan Asing dalam Bahasa Indonesia, 1968, hal. 34. 


\section{f. Kondisi Historis Kontak Bahasa ${ }^{47}$}

Dahulu orang Amerika merasa bahwa menggunakan bahasa lebih dari satu itu harus dihindari. Menurut mereka dengan berbahasa lebih dari satu akan mengurangi kecerdasan. Pendapat seperti ini sudah tidak relevan lagi. Karena adanya globalisasi, orang tidak dapat menghindari kontak budaya yang mengakibatkan kontak bahasa. ${ }^{48}$

Menurut Matsumoto ${ }^{49}$ bahwa orang yang hidup dengan keluarga yang menggunakan bahasa tertentu, maka orang tersebut akan berperilaku sesuai dengan budaya bahasa yang digunakan. Meskipun orang tersebut dwibahasawan, dengan kata lain ia akan menggunakan bahasa lain apabila berbicara dalam komonitas lain. Kontak Bahasa merupakan dampak dari adanya kontak budaya yang terjadi dalam masyarakat tertentu. Hal ini menyebabkan adanya sentuhan budaya lain kedalam budaya tertentu. Budaya tidak dapat dipisahkan dengan bahasa, karena sesuatu budaya akan dapat dipahami oleh budaya lain, apabila budaya tersebut mempunyai ciri khas dengan bahasa yang dijadikan alat komunikasi.

\section{g. Keperluan Pembedaan Nuansa Makna ${ }^{50}$}

Ada beberapa kata serapan bahasa Arab yang pada kesehariannya digunakan kata yang semakna dengannya. Meskipun kadang menyebabkan adanya perubahan bentuk pada kata Jawanya. Misalnya kata serapan aslinya berupa kata simpleks, tetapi setelah terserap kedalam bahasa Jawa menjadi kata kompleks, karena sudah dirubah menjadi padanannya.

\section{Kajian Fonologis Dalam Serat Centhini}

Fonologi adalah merupakan salah satu cabang linguistik yang menyelidiki bunyi bahasa dengan melihat fungsi bunyi sebagai pembeda arti dalam suatu bahasa ${ }^{51}$.

47 Matsumoto,David, Pengantar Psikologi Lintas Budaya, (Yogyakarta: Pustaka Pelajar, 2004), hal. 139-144.

48 David Matsumoto, Pengantar Psikologi Lintas Budaya, 2004, hal. 140- 141 dan bandingkan dengan Heah Lee Hsia, The Influence of English on the Lexical Expansion of Bahasa Malaysia, (Kuala Lumpur: Dewan Bahasa dan Pustaka,1989), hal. 18; Weinreich, Language in Contact and Problems, 1953, hal. 92.

49 David Matsumoto, Pengantar Psikologi Lintas Budaya, 2004, hal. 142.

50 Poedjosoedarmo, Soepomo, 1967, hal. 56.

51 Marsono, Fonologi Bahasa jawa dan Jawa Kuna, 2005 (Yogyakarta: UGM, buku hasil penelitian lanjutan; belum dipublikasikan), hal. 1, bandingkan dengan Mahmud Sa'ran, Ilmu al-Lughah, 1992, (Iskandariyah: Dar- al-Fikri al-Arabiy), hal. 91-92, kemudian bandingkan dengan Ferdinand De Saussure, Course in General Linguistics, 1966, (USA: McGraw-Hill Paperbacks), hal. 32-33. 
Secara struktural, kajian fonologi biasanya menggunakan tiga analisa utama, agar dapat memberikan pengetahuan tentang linguistik pada para penutur bahasa, yaitu: a. feature; ciri-ciri fonetis khusus dalam struktur linguistik, khususnya di bidang fonologi, b. segment; penggalan setelah lisan diubah menjadi tertulis, yang terdiri dari penggalan-penggalan bunyi (/d/,/1/,/s/ ), c. syllable/ silabel; merupakan hasil dua segmen atau lebih yang dikombinasikan, yang terdiri atas vokal dan konsonan yang berpasangan (kur-ma) ${ }^{52}$

Berbicara fonologi, maka tidak dapat terlepas dari pembahasan tentang fungsi fonem dalam bahasa Jawa dan bahasa Arab. Bahasa Jawa dan bahasa Arab adalah dua bahasa yang masing-masing mempunyai lambang khusus, sehingga apabila kedua bahasa tersebut ditranslit, maka transliterasinya akan menjadi unik. Serat Centhini yang asli berbahasa Jawa dan bertuliskan Jawa (ancrk), kemudian ditranslit atau ditulis ulang dengan tulisan latin. Salinan Latin yang masih diketik manual, bacaannya masih sesuai dengan bacaan aslinya. Akan tetapi, setelah dibukukan dengan pengeditan, maka bacaan dan tulisannya sudah ada yang berubah dan malahan ada yang hilang (tertinggal).

Perubahan fonologis dalam SC baik bacaan maupun tulisannya, berpengaruh terhadap perubahan bunyi kata serapan dari bahasa Arab kedalam SC. Hal ini menambah tingkat kesulitan pencarian dan pengumpulan data kata-kata serapan bahasa Arab yang masuk kedalam SC dan proses perubahannya. Sehingga data yang diperoleh banyak kemungkinan mengalami perubahan bunyi baik dari Arab aslinya maupun dalam penyalinannya. Pembahasan tentang perubahan bunyi seperti ini sebenarnya hanya pada kajian fonologi tentang perubahan fonemis dari fonemfonem suprasegmental ${ }^{53}$. Akan tetapi untuk membahas perubahan secara suprasegmental, tidak dapat jelas tanpa didahului dengan pembahasan tentang perubahan secara segmental.

Pembahasan tentang proses perubahan bunyi, maka secara analisis termasuk dalam pembahasan tentang perubahan bunyi akibat asimilasi fonemis. ${ }^{54}$ Meskipun

52 Mahmud Sa'ran, Ilmu al-Lughah, (Iskandariyah: Dar- al-Fikri al-”Arabiy, 1992), hal. 123-129.

53 Verhaar, Asas-asas Linguistik Umum, (Yogyakarta: Gajahmada University Press, 2004), hal. 77.

54 Verhaar, Asas-asas Linguistik Umum, (Yogyakarta: Gajahmada University Press, 2004) hal. 77. Di samping asimilasi fonemis, masih ada perubahan lain yang menyebabkan fonem tertentu menjadi fonem yang lain, yaitu: modifikasi vokal jenis umlaut, modifikasi vokal jenis ablaut, modifikasi vokal jenis harmoni vokal, netralisasi, hilangnya fonem dan kontraksi, disimilasi, dan metatesis. 
demikian, pembahasan secara fonetik akan membantu pada pembahasan secara fonemis. Dengan kata lain pembahasan secara fonemis tidak dapat dipisahkan dengan pembahasan tentang fonetik.

\section{E. Kajian Morfologis Kata Serapan Dalam Serat Centhini}

Proses penyerapan kata-kata Arab ke dalam SC, mengalami perubahan yang signifikan, karena SC asli ditulis dengan aksara ancrk, yang tidak semua aksaranya dapat dipadankan dengan huruf hijaiyah, sehingga tidak sedikit kata serapan bahasa Arab yang sudah berubah baik secara fonetik maupun fonemik. Secara artikulasi, kata dari bahasa Arab akan berbeda dengan artikulasi orang Jawa. Untuk mengetahui proses masuk dan perubahan kata serapan bahasa Arab kedalam SC, perlu dikaji secara morfologis, fonologis dan semantis. Apabila kata serapan dari bahasa Arab ditinjau dari bentuknya, maka ada yang berbentuk simpleks dan kompleks.

\section{Bentuk Simpleks}

Bahasa Arab mempunyai pola sukukata standar yaitu (1) KV, (2) KVK, (3) KVKK. ${ }^{55}$ Sementara pola sukukata bahasa Jawa adalah (1) V, (2) VK, (3) KV, (4) KVK. Pola sukukata KVKK merupakan sebuah kata, sebagai contoh kata / harf (huruf), / fikr (pikir) dan / bukm (hukum), pola pada contoh diatas tidak ada dalam pola sukukata bahasa Jawa. ${ }^{56}$

Menurut Muhammad Mandur, ${ }^{57}$ bahasa Arab membahas tentang kata turunan atau bentukan, yang disebut morphologi. Dalam bahasa Arab pembahasan tentang morfem ada tiga unsur yaitu; a. unsur bunyi, b. unsur makna, dan c. unsur kata di dalam kalimat. Untuk pembahasan morfologi dari kata serapan yang ada di dalam SC, peneliti fokuskan pada bentuk kata dari bahasa Arab yang terserap ke dalam SC yaitu : a. bentuk isim (nomina), b. bentuk fi'il (verba) dan c. bentuk huruf (partikel); untuk yang terakhir ini ditinjau dari sudut pandang bahasa Arab, karena dalam bahasa Jawa, huruf itu tidak ada maknanya, kecuali sesudah disusun menjadi sebuah kata.

55 Umar Sidik, Kosakata Bahasa Arab dalam Bahasa Jawa: Studi tentang Pola Penyerapan dan Penyimpangannya,( Yogyakarta: Balai Penelitian Bahasa, 1997/1998), hal. 71

56 Umar Sidik, 1997/1998, hal. 71.

57 D. Mandur, Muhammad, Manhaj al-Babts fi al-Adab wa al-Lughab,(Beirut: Dar al-iilm li alMalayin, tt), dalam Mahmud Sa'ran, 1992, hal. 216. 
Kata serapan bahasa Arab dalam SC yang berbentuk simpleks ${ }^{58}$, terdiri dari beberapa kategori yaitu: a. berbentuk isim (nomina), b. berbentuk fi'il (verba) dan c. berbentuk huruf (partikel)

\section{Bentuk Kompleks}

Pembahasa tentang bentuk yang berdasarkan bahasa Arab, akan dikaji secara morfologi Arab berdasarkan mîâan al-Shorf ${ }^{59}$ (bentuk-bentuk shorfiyah) Menurut mîâan al-Shorf, verba dalam bahasa Arab terbagi menjadi beberapa bentuk, ada yang mujarrad (bentuk yang masih asli, belum ada tambahan), kemudian ada yang berbentuk mazî̀ (sudah ada tambahan huruf dari bentuk aslinya). Untuk lebih jelasnya, lihat tabel auzân al-Shorf berikut

\section{Tabel 2. Bentuk Auzân al-Shorf ${ }^{60}$}

\begin{tabular}{|c|c|c|c|}
\hline No & $\begin{array}{c}\text { Perfek } \\
\text { (Madli) }\end{array}$ & $\begin{array}{l}\text { Imperfek } \\
\text { (Mudlari') }\end{array}$ & Makna Baru \\
\hline 1 & فa"ala & يفعَ" yufa"ilu & mentransitifkan \\
\hline 2 & فاعل fấala & بفاعل & $\begin{array}{l}\text { menunjukkan saling melaku kan pekerjaan dari verba } \\
\text { asal }\end{array}$ \\
\hline 3 & أفعل & 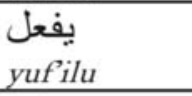 & mentransitifkan \\
\hline 4 & 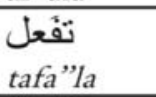 & yatafáalu & menunjukkan hasil pekerjaan dari verba fa'ala \\
\hline 5 & تفاعل & 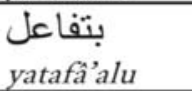 & $\begin{array}{l}\text { Menunjukkan hasil perkerjaan dilakukan bersama-sama } \\
\text { oleh pelaku dan objeknya }\end{array}$ \\
\hline 6 & $\begin{array}{l}\text { انفعل'ala } \\
\text { infáala }\end{array}$ & $\begin{array}{l}\text { yanfa'ilu } \\
\text { yailu }\end{array}$ & menunjukkan arti refleksif \\
\hline 7 & 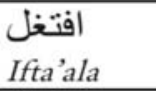 & بفتخل & menunjukkan hasil pekerjaan dari verba fa'ala \\
\hline 8 & ifalla & yaf'allu & menjukkan arti warna atau cacat \\
\hline 9 & استفعل & $\begin{array}{l}\text { بستفعل } \\
\text { yastafilu }\end{array}$ & untuk meminta apa yang disebut pada masdarnya \\
\hline
\end{tabular}

58 Bentuk simpleks adalah bentuk kata yang masih asli, belum mendapat afiks, baik afiks derivasional (proses pengimbuhan afiks pada dasar untuk membentuk kata), maupun afiks infleksional (unsur yang ditambahkan pada sebuah kata untuk menunjukkan suatu hubungan gramatikal).

59 Fuad Ni'mah, Mulakbkhash Qawâ'id al-Lughah al-'Arabiyyah, juz. II,(Damsik: Dar al-Hikmah, tt) hal. 6 .

60 Lihat Anton Dahdah, Mu'jam Qawa'id al-Lughah al-'Arabiyyah fi Jadwal wa Laubât, (Beirut: Maktabah Lubnan, 1981) hal.116-118, dan bandingkan dengan Haywood, A New Grammar of the Written Language, (London: Lund Humpharies, 1984), hal. 152, Al-Ghulayaini, 1973, hal. 224-225, dalam Samsul Hadi. 
Dari auzân al-Shorf tersebut di atas apabila terserap kedalam bahasa Jawa menjadi nomina, yang dalam bahasa Arab termasuk (kata-kata bentukan/ turunan), diantaranya;

\section{F. Kajian Semantis Kata Serapan Bahasa Arab Dalam Serat Centhini}

Secara Semantis kata serapan bahasa Arab dalam SC ada yang tetap sesuai aslinya, tetapi ada yang mengalami perubahan. Adapun proses perubahan semantis adalah sebagai berikut. Ada beberapa faktor penyebab perubahan makna, diantaranya adalah sebagai pembahasan berikut ini.

\section{Faktor Kesejarahan}

Dalam bahasa Jawa terdapat kata serapan drikir maulud yang maksudnya adalah puji-pujian untuk junjungan nabi besar Muhammad s.a.w, beliau lahir pada bulan Rabi'ul Awwal, dimana menurut istilah tahun Jawa disebut bulan Mulud (bersamaan maulud Nabi Muhammad pada 12 Rabi'ul Awwal); orang Jawa percaya $^{61}$ apabila pada kelahiran Rasulullah, sebaiknya dibacakan puji-pujian untuknya, sehingga pujia-pujian tersebut dinamakan dikir mulud/diki/mulux ${ }^{62}$ .( / dizikir maulud).

Kata $n$ raka $\left.a^{63} / n\right] k$ (<nar ) yang bermakna asli api atau sesuatu yang panas, karena terlalu umum, maka khusus nar (api) yang akan disediakan untuk manusia di akherat nanti, bagi yang berbuat maksiat dan dosa lainnya, maka orang Jawa sepakat khusus untuk api yang dijadikan balasan orang berdosa adalah nraka (Indonesia $=$ neraka). Melihat arti tersebut, berarti bermakna menyempit dan khusus, meskipun demikian, orang akan faham apabila disebut nraka. Orang tahu bahwa itu tempat pembalasan orang yang berbuat dosa.

${ }^{61}$ Diadopsi dari Rich

${ }^{62}$ Kamajaya, SC VI, 1988, hal. 93, dalam SC disebutkan bahwa tujuan zikir mulud tersebut adalah untuk menghormat Nabi Muhammad agar mendapat barakah dan syafaatnya. Sementara dalam cerita SC pada waktu itu bertepatan pernikahan antara Amangraga dan Tembangraras, dimana orangtua Tembangraras minta kepada penghulunya agar membacakan dhikir mulud. Dan bandingkan dengan D. Abd al-Karim Mujahid,tt, Al-Dilâlah al-Lughawiyah 'inda al-'Arab, tt., hal. 17.

${ }^{63}$ Istilah ini sudah menjadi kata serapan yang sudah menyempit artinya; oleh karena itu, biasanya nraka dikaitkan dengan nama-nama tempat pembalasan orang berdosa diakherat; seperti nraka Jahanam, nraka Sangir dan sebagainya. 
Kata dhikir ${ }^{64}$ dikil $(<d z i k r \quad)$ dahulu bermakna mengingat atau menghapal. Karena proses penyerapan sekarang kata itu memiliki makna lain yakni (a) do'a; pujian (perkataan baik); (b) permohonan; permintaan; (c) do'a-do'a orang sesudah sholat, (d) puji-pujian kepada Nabi Muhammad.

\section{Perubahan Lingkungan}

Lingkungan masyarakat dapat menyebabkan perubahan makna suatu leksem. Bahasa yang digunakan pada lingkungan masyarakat tertentu dapat mempunyai makna lain jika digunakan pada lingkungan yang lain. ${ }^{65}$ Karena faktor kebutuhan kata-kata baru yang disebabkan adanya perkembangan suatu bahasa menyebabkan sebuah kata yang juga dipakai sebagai istilah dipergunakan dalam lingkungan sosial yang lebih luas, tidak hanya tertentu dalam bidang yang pertama kali menggunakannya.

Perubahan makna akibat perubahan lingkungan ini merupakan perubahan yang disebabkan oleh faktor sosial. Perubahan ini terjadi akibat pemakaian kata atau istilah oleh berbagai kelompok sosial yang berbeda. Pemakaian tersebut memungkinkan perubahan makna dari makna asalnya.

Sebagai contoh adalah ngalim/ zlim $\backslash(\quad)$ arti asalnya adalah orang yang mengetabui atau orang yang pandai. Kata ini dalam bahasa Jawa menyempit pemakaiannya di lingkungan sosial tertentu, yakni lingkungan sosial keagamaan. Maknanya kemudian menjadi (a) berilmu; berpengetahuan, pandai (dalam hal agama Islam); (b) saleh; tidak nakal. Kata alim kemudian juga sering digabungkan dengan bentuk jamaknya yakni ngulama / zulm ( ), sehingga terdapatlah frase ngalim-ngulama / zllim \zulm /'âlim 'ulama) yang berarti orang-orang yang pandai/ahli dalam bidang agama Islam, kaum cerdik padai dalam ilmu agama atau penyiar agama.

\section{F. Penutup}

Dari uraian di atas tentang proses penyerapan kata bahasa Arab kedalam Serat Centhini (SC), maka temuan yang peneliti dapat adalah secara filosofis; secara

${ }^{64}$ Kamajaya, SC V, 1988, hal. 69, di dalam SC disebutkan; hendaknya manusia banyak berdzikir dan memuji, agar mendapatkan apa yang dicari.Kemudian di SC VI disebutkan tentang dzikir Maulud, yang tujuannya agar mendapat barakah dan syafa'atnya Nabi Muhammad, dengan banyak puji-pujian kepadanya.

${ }^{65}$ Pateda, Mansoer, Semantik Leksikal, (Ende: Nusa Indah, 1986), hal.75 dan lihat D. Abd alKarim Mujahid,tt, Al-Dilâlah al-Lughawiyah 'inda al'A Arab, tt., hal. 17 dan bandingkan dengan D. Ahmad Mudzakir Umar, Ilmu al-Dilâlah, (Kuwait: Maktabah Dar al-'Arabiyah, 1982), hal. 214. 
linguistik dapat disimpulkan bahwa "Tidak setiap kata serapan yang berubah bunyi dan atau bentuk, menyebabkan perubahan makna”. Hal ini setelah peneliti cari dan temukan, maka yang terjadi adalah sebagai berikut:

1. Terjadinya perubahan bunyi kata serapan dalam SC adalah disebabkan karena sistem bunyi antara Jawa dengan aksara Jawa (ancrk ) dan Arab dengan huruf hijaiyah ( , , ) tidak semuanya dapat dipadankan, sehingga ada beberapa bunyi Arab yang harus disesuaikan kedalam bunyi Jawa, maka terciptalah aksara rekan yaitu; / Ý/ menjadi / $p+$ /, / / menjadi / j+ /, / / menjadi / k+ /,/ /menjadi / $g+/$,dan yang terakhir / / menjadi / $f+/$. Selain itu, perubahan bunyi kata serapan bahasa Arab juga disebabkan perbedaan sistem dan daerah artikulasi antara bunyi Arab dengan bunyi Jawa.

2. Sementara perubahan bentuk kata serapan bahasa Arab dalam SC, disebabkan perbedaan leksem dan perbedaan proses perubahan bentuk antara bahasa Arab dengan bahasa Jawa.

3. Perubahan makna kata serapan bahasa Arab dalam SC, disebabkan oleh konteksnya. Secara historis, adanya kata serapan bahasa Arab kedalam SC (sebanyak kurang lebih 7\%) adalah karena terjadinya kontak budaya antara Islam dan Jawa, dan sebab masuknya budaya sebelum Islam. Akibat kontak budaya menyebabkan kontak bahasa, dan dari kontak bahasa menyebabkan terjadinya dwibahasawan.

Adapun penemuan Rasyidi dalam disertasinya yang menyatakan bahwa bahasa Arab yang ada dalam SC telah menyimpang dari ajaran Islam yang murni, itu karena beliau dalam penelitiannya menggunakan pendekatan Syari'at Islam, sementara penelitian yang penulis lakukan menggunakan pendekatan dan landasan teori ilmu bahasa (linguistik).

\section{DAFTAR PUSTAKA}

Adji, Fransisca Tjandrasih. 2006. "Karya-karya Zoetmulder dan Sejarah Sastra Jawa", makalah Seminar Nasional "Meninjau Kembali Kajian Jawa” dalam rangka memperingati 100 tahun Prof. Dr. Zoetmulder, S.J. USD, 9-10 Februari.

Almanar, Alma Evita. 2005. Bahasa Melayu Bahasa Dunia (penerjemah) dari Malay World Language: a short history (James T. Collins). Jakarta: Yayasan Obor Indonesia. 
Agustina, Abdul Chaer dan Leonie . 2004. Sosiolinguistik- Perkenalan Awal. Bandung: Angkasa.

Dahdah, Anton. 1981. Mu'jam Qawâid al-Lughah al-'Arabiyyah fi Jadwal wa Lauhât. Beirut: Maktabah Lubnan.

Baroroh-Baried. 1970. Bahasa Arab dan Perkembangan Babasa Indonesia. Yogyakarta: UGM.

Chaer, Abdul. 1995. Linguistik Umum. Jakarta: PT. Rineka Cipta.

Mujahid, D. Abd al-Karim. Tanpa tahun. Al-Dilâlah al-Lughawiyah 'inda al-'Arab.

Umar, D. Ahmad Mudzakir. 1982. Imu al-Dilâlah. Kuwait: Maktabah Dar al'Arabiyah.

D. Mandur, Muhammad. Tanpa tahun. Manhaj al-Babts fi al-Adab wa al-Lughah. Beirut: Dar al-'ilm li al-Malayin.

Saussure, Ferdinand De. 1966. Course in General Linguistics. USA: McGraw-Hill Paperbacks.

Ni'mah, Fuad. Tanpa tahun. Mulakhkhash Qawâ'id al-Lughah al-Arabiyyah, juz. II. Damsik: Dar al-Hikmah.

Hamidy. 2004. Metode Penelitian Kualitatif. Malang: Universitas Muhammadiyah Malang.

Haugen, Einar. 1972. The Ecologi of Language. Stanford: Stanford University Press. Haywood. 1985. A New Grammar of the Written Language. London: Lund Humpharies.

Indandiak, Elizabeth D. 2004. Minggatnya Cebolang, terj. Lesmana Laddy. Yogyakarta: Galang Press.

Kamajaya. 1998. Serat Centhini (Suluk Tambangraras). Yogyakarta: Yayasan Centhini.

Kamajaya Pk., H. Karkono. 1998. “Serat Centhini Relevasinya dengan Masa Kini”. Makalah dari Ceramah, di Balai Pustaka pada hari Jum'at Pon, 2 September. Mahmud Sa'ran, 1992. Ilmu al-Lughah. Iskandariyah: Dar- al-Fikri al-Arabiy. Marsono. 2005. Fonologi Bahasa Jawa dan Jawa Kuna. Yogyakarta: UGM. 
Marsono. 2006. Kearifan Lokal dalam Perubahan Lingkungan pada Manuskrip dan Tradisi Lisan. Makalah workshop, di hotel Saphir pada tanggal 22-23 September.

Matsumoto, David. 2004. Pengantar Psikologi Lintas Budaya. Yogyakarta: Pustaka Pelajar.

Moeliono. 1968. Masalah Asli dan Asing dalam Bahasa Indonesia.

Lubis, Nabilah. 1991. Suntingan Naskah Zubdaz al-Asrar fi Tahqiq Ba'd Masyarib al-Akbyar Karya Syeh Yusuf A-Taj. Jakarta: Disertasi, IAIN Syarif Hidayatullah.

Ngabei Ranggasutrasna, dkk. 1999. Centhini Tambangraras- Amongraga. Jakarta: Balai Pustaka.

Paina, Partana (penerj). 2003. Semantik, dari Semantics. (Leech, Geofferey), Yogyakarta: Pustaka Pelajar.

Pateda, Mansoer. 1986. Semantik Leksikal. Ende: Nusa Indah.

Poedjosoedarmo, Soepomo. 1967. Indonesian Influence on Javanese. A Thesis, Cornell University.

Riyadi, Slamet. 1966. Ha- Na- Ca- Ra- Ka (Kelabiran, Penyusunan, Fungsi dan Makna. Surabaya: Yayasan Pustaka Nusantara.

Shofwani, M. Irfan. 2005. Mengenal Tulisan Arab Melayu. Yogyakarta: Adicita.

Sudaryanto (Peny.). 1991. Tata Bhasa Baku Bahasa Jawa. Yogyakarta: Duta Wacana University Press.

al-Attas, Syed Naguib. 1969. Preliminary Statement on A General Theory of The Islamisation of The Malay-Indonesion Archipelago. Kuala Lumpur: Dewan Bahasa dan Pustaka.

Sidik, Umar. 1997. Kosakata Babasa Arab dalam Bahasa Jawa: Studi tentang Pola Penyerapan dan Penyimpangannya. Yogyakarta: Balai Penelitian Bahasa.

Van der, Molen W. 1985. "Sejarah dan Perkembangan Aksara Jawa", dalam Soedarsono dkk. (peny). Aksara dan Ramalan Nasib dalam Budaya Jawa. Yogyakarta: Proyek Javanologi. 
Kajian Morfosemantis terbadap Serat Centhini 125

Verhaar. 2004. Asas-asas Linguistik Umum. Yogyakarta: Gajahmada University Press.

Weinreich. 1953. Language in Contact and Problems.

Zoetmulder. 1994. Kalangwan: Sastra Jawa Selayang Pandang. Jakarta: Djambatan. 
126 Millah Vol. X, No. 1, Agustus 2010 